\title{
Tribological Characterisation of Graphene Oxide as Lubricant Additive on Hypereutectic Al-25Si/Steel Tribopair
}

\section{Parveen Kumar \& M. F. Wani}

To cite this article: Parveen Kumar \& M. F. Wani (2017): Tribological Characterisation of Graphene Oxide as Lubricant Additive on Hypereutectic Al-25Si/Steel Tribopair, Tribology Transactions, DOI: 10.1080/10402004.2017.1322735

To link to this article: http://dx.doi.org/10.1080/10402004.2017.1322735

Accepted author version posted online: 28

Apr 2017.

Published online: 28 Apr 2017.

Submit your article to this journal $\pi$

Џ Article views: 51

Q View related articles $\widetilde{ }$

View Crossmark data $\nearrow$ 


\title{
Tribological Characterisation of Graphene Oxide as Lubricant Additive on Hypereutectic Al-25Si/Steel Tribopair
}

\author{
Parveen Kumar and M. F. Wani \\ Tribology Laboratory, Department of Mechanical Engineering, National Institute of Technology Srinagar, Hazratbal Srinagar, Kashmir, India
}

\begin{abstract}
The performance of a lubricant greatly depends on the additives it involves. However, recently used additives produce severe pollution when they are burned and exhausted. Therefore, it is necessary to develop a new generation of green additives. Graphene oxide (GO) is considered to be environmentally friendly. The scope of this study is to explore the fundamental tribological behavior of graphene, the first existing 2D material, and evaluate its performance as a lubricant additive. The friction and wear behavior of 0.5 wt $\%$ concentrations of GO particles in ethanol and SAE20W50 engine oil on a hypereutectic Al-25Si alloy disc against steel ball was studied at $5 \mathrm{~N}$ load. GO as an additive reduced the wear coefficient by 60$80 \%$ with $30 \mathrm{~Hz}$ frequency for $120 \mathrm{~m}$ sliding distance. The minimum value of the coefficient of friction (0.057) was found with SAE20W50 + $0.5 \mathrm{wt} \%$ GO. A possible explanation for these results is that the graphene layers act as a 2D nanomaterial and form a conformal protective film on the sliding contact interfaces and easily shear off due to weak Van der Waal's forces and drastically reduce the wear. Scanning electron microscopy (SEM), energy-dispersive spectroscopy (EDS), and Raman spectroscopy were used for characterization of $\mathrm{GO}$ and wear scars.
\end{abstract}

ARTICLE HISTORY

Received 10 December 2016 Accepted 18 April 2017

\section{KEYWORDS}

Synthesis; graphene oxide; tribology; friction; wear and lubrication

\section{Introduction}

Energy resources are depleting at a very fast rate throughout the world, and designers and engineers are under tremendous pressure to explore all available alternatives to develop innovative and creative technologies to conserve energy and materials and preserve the environment. The main reason behind energy loss in a mechanical system is friction (Yoshizawa, et al. (1)). One of the most appropriate methods to reduce friction and wear in mechanical systems is using mineral oil-based lubricants (Willing (2)). However, due to the inherent toxicity and nonbiodegradable nature of mineral oil, the need to develop environmentally friendly lubricating fluids is increasing (Mercurio, et al. (3); Bartz (4)).

Nanoparticles as base oil additives in the field of tribological applications have been extensively investigated (Bartz (4)). The synthesis and preparation of nanoscale particles and their tribological properties and friction and wear reduction mechanisms have been investigated (Greenberg, et al. (5); Joly-Pottuz, et al. (6); Yadgarov, et al. (7)). It has been found that when nanoparticles were added to base oil, the load-carrying capacity and extreme pressure property were improved and the friction coefficient and wear rate were reduced. At elevated temperatures, nested spherical supramolecules of metal dichalcogenide have been prepared by the reaction of metal oxide nanoparticles with $\mathrm{H}_{2} \mathrm{~S}$. Due to their nested fullerene-like structure, these species are called inorganic fullerene-like (IF) nanoparticles. The IF nanoparticles exhibited improved tribological properties compared to the microscale platelets due to their better characteristics and flexibility, and they act as rollers on the surface, which prevents direct metal-to-metal contact and reduces friction and wear. Various researchers have investigated the tribological properties of fullerene-like nanoparticles as liquid lubricant additive (Greenberg, et al. (5); Joly-Pottuz, et al. (6); Yadgarov, et al. (7); Rosentsveig, et al. (8); Barnhill, et al. (9)). The tribological behavior of a lubricant (SAE15W40) containing different $(0.1,0.5$, and $1.0 \mathrm{wt} \%)$ concentrations of boron nitride nanoparticles has been studied in Wan, et al. (10). In this research study, it has been observed that the addition of nano-BN particles to SAE15W40 significantly improve the antifriction and antiwear properties of the SAE15W40 oil. Recently, tribological studies with the addition of different weight percentages of IF-MoS ${ }_{2}$ in SAE20W40 and h-BN nanoparticles in SAE20W50 engine oil were conducted (Charoo and Wani (11), (12)). In these research studies, it has been observed that the addition of nanoparticles to engine oil significantly improved the tribological performance in internal combustion (IC) engine applications.

However, investigations into the ideal lubricant that provides the lowest friction and wear in combination with the lowest toxicity continue (Khorramian, et al. (13)). An energizing new material that has been explored widely for its large number of unusual mechanical, physical, and electrical properties is graphene and a crystallographically perfect film of graphitic carbon (Peng, et al. (14); Schwarz, et al. (15); Yu, et al. (16)). The

CONTACT M. F. Wani mfwani@nitsri.net

Color versions of one or more of the figures in the article can be found online at www.tandfonline.com/utrb.

Review led by Ashlie Martini.

๑) 2017 Society of Tribologists and Lubrication Engineers 
few studies circulated in the open literature have mainly concentrated on the nano- and microscale aspects (Lee, et al. (17); Gómez-Navarro, et al. (18); Gao and Hao (19)) specifically utilizing a friction force microscopy technique (Lee, et al. (20); Deng, et al. (21)). Further, very few statistics are available on the macroscale tribological properties of graphene. Kandanur, et al. (22) have demonstrated that graphene platelets as a composite additive drastically reduce wear rates in polytetrafluoroethylene; graphene imparts excellent wear resistance to the resultant composite material. In implants, graphitic layers (which help to improve the friction and wear in artificial joints) have additionally been recognized in CoCrMo on CoCrMo alloy (metal-on-metal) hip replacements (Liao, et al. (23)). Graphene platelets have been utilized as an oil additive for enhanced lubricity and wear resistance (Lin, et al. (24)). Additionally, graphene is an excellent corrosion protection layer on refined metals-for example, copper and nickel (Prasai, et al. (25); Chen, et al. (26)) —utilized in reactive environments condition for mechanical applications. Recently, various studies have been reported on the wear behavior of graphene as a lubricant additive. Berman, et al. (27), (28) reported dramatic reductions in friction and wear of steel-against-steel tribopairs that were continuously lubricated with graphene layers under humid air and dry nitrogen conditions. Fan and Wang (29) reported the improvement in friction due to high-performance lubricant additives based on modified graphene oxide by ionic liquids. In addition, Kinoshita, et al. (30) and Zheng, et al. (31) investigated monolayer graphene oxide (GO) sheets as waterbased lubricant additives and as oil additives on a stainless steel flat plate and cast iron plate and found dramatic reductions in friction and wear properties. In addition, Senatore, et al. (32) and Sarno, et al. (33) studied the effect of GO sheets as additives in oil-based lubricants. In these research studies, it was observed that the reduction in the coefficient of friction (COF) was not remarkable, but the antiwear property of the lubricant was largely improved. Fan, et al. (34) dispersed GO ranging from 0.05 to $1 \mathrm{wt} \%$ in poly alpha olefin/bentone grease and found better results $(\sim 1-2 \%)$ with $0.5 \mathrm{wt} \%$ of GO. The addition of GO not only improved the friction and wear characteristics of bentone grease but increased its thermal stability and loadbearing capacity (Fan, et al. (34)). Moreover, Zhe, et al. (35) studied the performance of $0.5 \mathrm{wt} \%$ GO in hydrocarbon base oil for steel-on-steel up to a temperature of $150^{\circ} \mathrm{C}$ and observed that the COF and wear rate of steel significantly reduced with an increase in temperature. These studies show that graphene has great potential as a self-lubricating material that will combat wear and friction-related energy and material losses in different dry and lubricated tribological applications.

Friction losses in an IC engine not only reduce its efficiency but also increase the emission level (Barnhill, et al. (9); Wan, et al. (10); Charoo and Wani (11), (12)). In order to increase efficiency and reduce emissions, alternative and appropriate solutions for reducing friction and wear in an IC engine should be developed. This objective can be achieved by using an efficient material or a better lubricant or by adopting a synergetic approach. It is well known that $\mathrm{Al}-\mathrm{Si}$ alloy materials are used in a number of tribological applications in vehicles, such as pistons, cylinder liners, compressor scrolls, and engine blocks, and different engineering sectors.
It is evident from the above literature review that graphene has been effective in reducing friction and wear to a large extent when applied at the interface in a tribosystem (Kandanur, et al. (22); Liao, et al. (23); Lin, et al. (24); Prasai, et al. (25); Chen, et al. (26); Berman, et al. (27), (28); Fan and Wang (29); Kinoshita, et al. (30); Zheng, et al. (31); Senatore, et al. (32); Sarno, et al. (33); Fan, et al. (34); Zhe, et al. (35)). However, no research studies have been carried out to study the influence of graphene on the friction and wear characteristics of a hypereutectic Al-25Si alloy.

In the present study, tribological studies were conducted to study the influence of graphene oxide on the friction and wear properties of a hypereutectic Al-25Si alloy. First, synthesis and characterization of GO were conducted. The tribological behavior of GO particles in ethanol and SAE20W50 engine oil was investigated on a hypereutectic Al-25Si alloy against AISI 52100 bearing steel tribopairs under boundary-lubricated conditions. A ball-on-disc universal tribometer was used for all experimental studies. Scanning electron microscopy (SEM), energy-dispersive spectroscopy (EDS), and Raman spectroscopy were used for characterization of GO and wear tracks. In addition, the morphologies of the worn surfaces of the hypereutectic Al-25Si alloy were analyzed using a 3D surface profilometer and optical microscope.

\section{Experimental details}

The properties and structure of GO depend on the synthesis method and degree of oxidation. The most common method of synthesis is Hummer's method and a modified Hummer's method (Senatore, et al. (32); Chandra and Kim (36); Paulchamy, et al. (37)). In this study, GO nanosheets were prepared by an improved method of synthesis, namely, the improved Tour method (Marcano, et al. (38)).

\section{Materials}

Hypereutectic Al-25Si alloy, AISI 52100 bearing steel, graphite powder (acid treated 99\%), potassium permanganate $(99.5 \%)$, sulfuric acid (98\%), phosphoric acid, hydrogen peroxide (30\%), hydrochloric acid (35\%), deionized water, and ethanol were purchased from commercially available reliable sources.

\section{Synthesis of graphene oxide}

Graphene oxide was synthesized by the improved Tour method through oxidation of graphite powder (Marcano, et al. (38)). Graphite powder $(3 \mathrm{~g})$ and potassium permanganate $\left(\mathrm{KmNo}_{4}\right.$; $2 \mathrm{~g})$ were mixed in 360 and $40 \mathrm{~mL}$ sulfuric acid $\left(\mathrm{H}_{2} \mathrm{SO}_{4} ; 98 \%\right)$ and phosphoric acid $\left(\mathrm{H}_{3} \mathrm{Po}_{4}\right)$, respectively. The mixture was stirred for $12 \mathrm{~h}$ at $5^{\circ} \mathrm{C}$ and then cooled down. Ice and $4 \mathrm{~mL}$ of hydrogen peroxide $\left(\mathrm{H}_{2} \mathrm{O}_{2}\right)$ were added to the suspension very slowly and stirred continuously. The addition rate of $\mathrm{H}_{2} \mathrm{O}_{2}$ was carefully controlled to keep the reaction temperature lower than $15^{\circ} \mathrm{C}$. The mixture was stirred for about $1 \mathrm{~h}$ at $5-10^{\circ} \mathrm{C}$ until the orange color changed to a brown color. For purification, the solution was washed with a mixture of $20 \%$ hydrochloric acid $(\mathrm{HCl})$ and $80 \%$ water $\left(\mathrm{H}_{2} \mathrm{O}\right)$ and finally filtered with $70 \mathrm{~mL}$ of ethanol. After filtration and drying at room 
temperature, the GO flakes were obtained. GO flakes were converted into powder by ball milling for $15 \mathrm{~h}$.

\section{Tribological tests description}

Tribological tests on the hypereutectic $\mathrm{Al}-25 \mathrm{Si}$ alloy disc against AISI 52100 bearing steel ball were performed in air (50\% relative humidity) at room temperature using a universal tribometer (Fig. 1) with a ball-on-disk contact geometry. The composition and mechanical properties of hypereutectic Al-25Si alloy are given in Tables 1 and 2. Cylindrical specimens of $35 \mathrm{~mm}$ diameter and $8 \mathrm{~mm}$ thickness were cut from the rod. The surface preparation procedure consisted of grinding disc surfaces and then final polishing. Grinding was carried out using $\mathrm{SiC}$ papers of $800-, 1,000-, 1,200-$, and 2,000-grit sizes, and final mirror finishing was achieved with $4-, 1-$, and $0.25-\mu \mathrm{m}$ diamond pastes. The hypereutectic Al-25Si alloy samples were initially cleaned by sonication in acetone and then in benzene to remove any chemical contaminants that may have been left during sample preparation. An average surface roughness $\left(R_{a}=0.036 \mu \mathrm{m}\right)$ was achieved as measured by the $3 \mathrm{D}$ surface profilometer. The counterpart AISI 52100 bearing steel ball of $9.5 \mathrm{~mm}$ diameter with an average surface roughness $R_{a}=0.04 \mu \mathrm{m}$ as measured by the $3 \mathrm{D}$ surface profilometer was used. The normal load during the tribotests was $5 \mathrm{~N}$ at a frequency of $30 \mathrm{~Hz}$. The sliding test duration was $16.66 \mathrm{~min}$ with a sliding distance of $120 \mathrm{~m}$ and stroke of $2 \mathrm{~mm}$.

In this study, $0.5 \mathrm{wt} \% \mathrm{GO}$ was dispersed in ethanol and SAE20W50 oil as the lubricant followed by stirring with a magnet for $1 \mathrm{~h}$ at room temperature and sonication for $2 \mathrm{~h}$ at a temperature of $50^{\circ} \mathrm{C}$ and frequency of $40 \mathrm{kHz}$ to disperse the GO particles uniformly. Considering the difficulty in preparing stable dispersions of GO particles, all experiments were carried out immediately after ultrasonication to avoid agglomeration of the GO particles dispersed in the lubricant. A small amount (one drop or $0.1-0.12 \mathrm{~mL}$ of solution) was applied on the highly polished surface of the hypereutectic Al-25Si alloy disc before starting the test. The experiments were also conducted with ethanol and SAE20W50 base oil to provide a baseline for comparison. Each test was conducted three times and the average values were taken. After the tests, the hypereutectic Al-25Si alloy disc and steel ball were cleaned with acetone and benzene to completely remove all of the debris and lubricant materials for analysis of the wear scars. The microstructures of the materials were studied using optical microscopy and SEM.

To estimate the wear coefficient after the tests, we calculated the wear volume of the disc. The wear coefficient $\left(K_{w}\right)$ was determined by the ratio of the wear volume $\left(\mathrm{mm}^{3}\right)$ per unit sliding distance $(\mathrm{m})$ per unit applied normal load $\left(F_{n}\right)$ and is given as

$$
K_{w}=\frac{W_{v}}{\left(S_{d} \times F_{n}\right)} \frac{\mathrm{mm}^{3}}{\mathrm{~N} \cdot \mathrm{m}}
$$

where $W_{v}$ is the wear volume $\left(\mathrm{mm}^{3}\right), S_{d}$ is the sliding distance $(\mathrm{m})$, and $F_{n}$ is the load applied $(\mathrm{N})$.

\section{Characterization methods}

The GO synthesized by the improved Tour method and wear tracks of hypereutectic Al-25Si alloy were characterized by SEM with EDS and Raman spectroscopy with $532 \mathrm{~nm}$ wavelength, $50 \mathrm{mV}$ laser power, and $50 \times$ objective with a 60 -s exposure time with single accumulation. Raman spectroscopy analysis on the hypereutectic $\mathrm{Al}-25 \mathrm{Si}$ alloy surfaces was performed to investigate the presence of $\mathrm{GO}$ on the surfaces after tribological tests and to verify the formation of a protective film on the rubbing surfaces due to the GO particles. In addition,
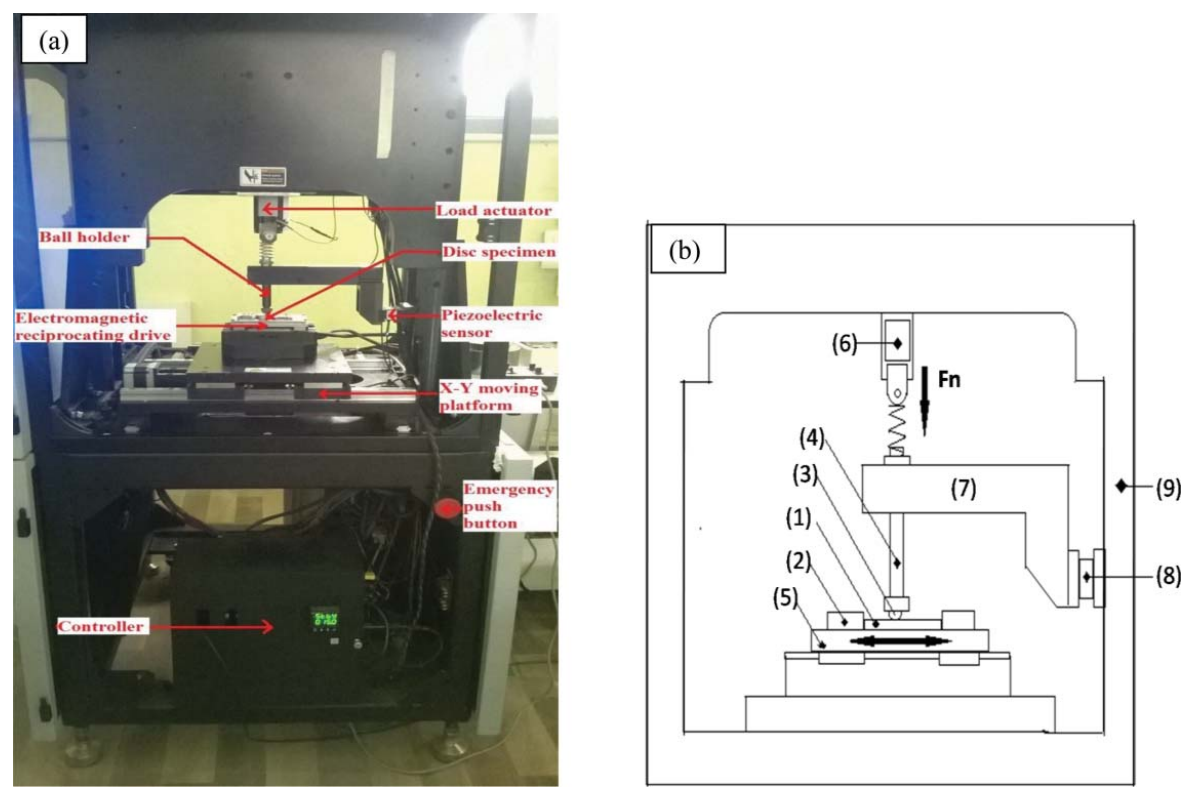

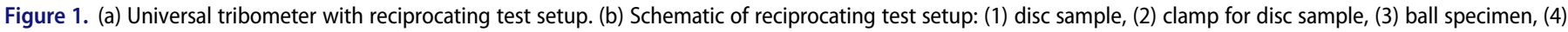
ball holder, (5) electromagnetic reciprocating drive, (6) load actuator, (7) loading arm, (8) piezoelectric sensor, and (9) supporting frame. 
Table 1. Chemical composition of hypereutectic Al-25Si alloys.

\begin{tabular}{lccccc}
\hline & & \multicolumn{4}{c}{ Chemical composition (wt \%) } \\
\cline { 3 - 6 } Alloy & Fabrication technique & $\mathrm{Si}$ & $\mathrm{Cu}$ & $\mathrm{Mg}$ & $\mathrm{Al}$ \\
\hline Al-25Si & Rapid solidification & 25 & 4 & 1 & Balance \\
\hline
\end{tabular}

Table 2. Mechanical properties of hypereutectic Al-25Si alloys.

\begin{tabular}{lcccccc}
\hline Material & $\begin{array}{c}\text { Tensile } \\
\text { strength } \\
(\mathrm{MPa})\end{array}$ & $\begin{array}{c}\text { Yield } \\
\text { strength } \\
(\mathrm{MPa})\end{array}$ & $\begin{array}{c}\text { Poisson's } \\
\text { ratio }\end{array}$ & $\begin{array}{c}\text { Elongation } \\
(\%)\end{array}$ & $\begin{array}{c}\text { Elastic } \\
\text { modulus } \\
(\mathrm{GPa})\end{array}$ & $\begin{array}{c}\text { Hardness } \\
(\mathrm{HV})\end{array}$ \\
\hline Al-25Si & 480 & 441 & 0.29 & 0.7 & 96 & 210 \\
\hline
\end{tabular}

the morphologies of the worn surfaces of the hypereutectic Al$25 \mathrm{Si}$ alloy were analyzed using a $3 \mathrm{D}$ surface profilometer and optical microscope.

\section{Results and discussion}

\section{Scanning electron microscopy}

Figure 2 shows SEM morphology of graphite and GO particles. Figures $2 \mathrm{a}$ and $2 \mathrm{c}$ and Figs. $2 \mathrm{~b}$ and $2 \mathrm{~d}$ show SEM micrographs of typical graphite powder and the exfoliated GO particles respectively at low magnification and high magnification. From the SEM images, it is clear how the sheets are stalked together and how the graphene sheets are exfoliated. It can be seen that the lateral dimensions of most of GO sheets range from hundreds of nanometers to a few micrometers. SEM micrographs confirm the formation of GO nanosheets. Similar results were obtained in research by Senatore, et al. (32).
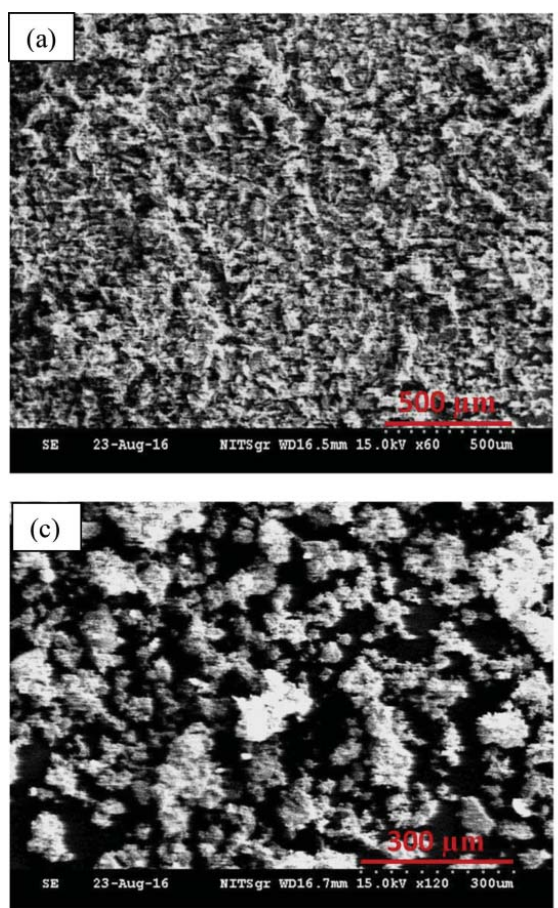

\section{Raman spectrum analysis}

Raman spectroscopy is mainly used for the characterization of carbon materials, especially considering the fact that conjugated and double C-C bonds lead to high Raman intensities. Figure 3 shows the Raman spectrum of GO, where the $\mathrm{G}$ band peak of GO is at $1598 \mathrm{~cm}^{-1}$ and the disorder band (D band) peak of GO is at $1347 \mathrm{~cm}^{-1}$. The presence of two band peaks (D and $G$ ) in the Raman spectrum confirms the successful synthesis of GO. It has already been established that the D band is a common feature of $\mathrm{sp}^{3}$ defects in carbon, and the $\mathrm{G}$ band provides information on plane vibrations of $\mathrm{sp}^{2}$-bonded carbons. This confirms the formation of graphene oxide (Fan and Wang (29); Kinoshita, et al. (30); Zheng, et al. (31); Senatore, et al. (32); Sarno, et al. (33); Fan, et al. (34); Zhe, et al. (35); Chandra and Kim (36); Paulchamy, et al. (37); Marcano, et al. (38); Chu, et al. (39)).

\section{Tribological characterization in dry and lubricated sliding conditions}

Friction and wear tests were performed on a hypereutectic Al25Si alloy disc against a steel ball in dry and lubricated conditions and the results of friction and wear studies are discussed in the following sections.

\section{Coefficient of friction}

Tribological tests were conducted to study the effect of GO on the friction and wear characteristics of hypereutectic Al-25Si alloy against a steel ball at room temperature. In these studies, three types of experiments were conducted: (1) hypereutectic $\mathrm{Al}-25 \mathrm{Si}$ alloy against a steel ball in dry condition, (2)
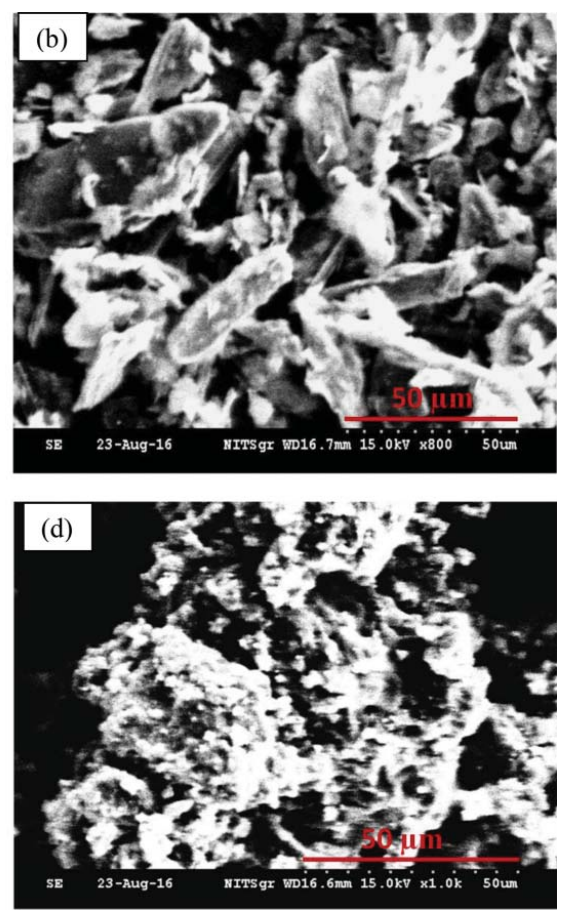

Figure 2. SEM micrographs (a) graphite powder at low magnification, (b) graphite powder at high magnification (c) GO powder at low magnification, (d) GO powder at high magnification. 


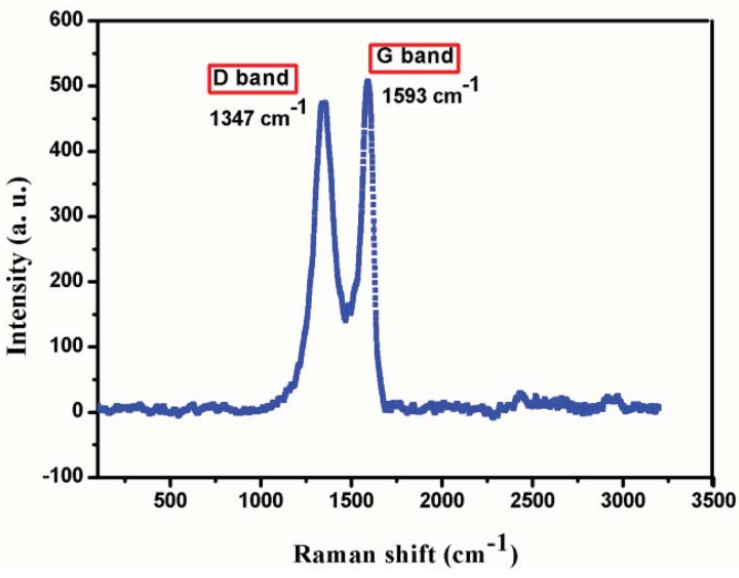

Figure 3. Raman spectrum of GO powder.

hypereutectic $\mathrm{Al}-25 \mathrm{Si}$ alloy against a steel ball in ethanol with and without GO particles, and (3) hypereutectic Al-25Si alloy against a steel ball in SAE20W50 engine oil with and without GO particles. Each test was conducted three times and the average values were taken. Results of the COF obtained from these experimental studies are shown in Fig. 4.

The COF for hypereutectic Al-25Si alloy against a steel ball in dry sliding condition was initially high (0.5) for a few seconds then decreased rapidly and attained a steady state value of 0.22 . Constant COF values of 0.20 and 0.16 were observed in the case of ethanol and ethanol $+0.5 \mathrm{wt} \% \mathrm{GO}$, respectively, whereas constant COF values of 0.079 and 0.057 were attained in the case of SAE20W50 and SAE20W50 + $0.5 \mathrm{wt} \%$ GO, respectively. It is clear from Fig. 4 that the highest COF value of 0.22 was obtained under dry sliding conditions, whereas the lowest COF value of 0.057 was attained in the case of SAE20W50 + $0.5 \mathrm{wt} \%$ GO.

\section{Wear behavior}

The wear volume of hypereutectic Al-25Si alloy disc was calculated by a weight loss method. The weight of disc was measured using an electronic balance accurate up to $100 \mu \mathrm{g}$. In all tests,

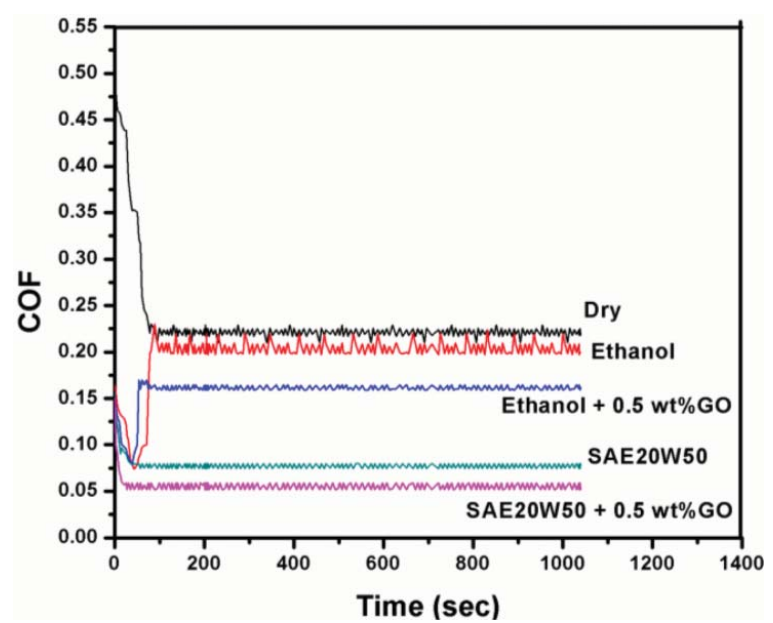

Figure 4. Coefficient of friction vs. time (s) of a hypereutectic Al-25Si alloy disc against a bearing steel ball.

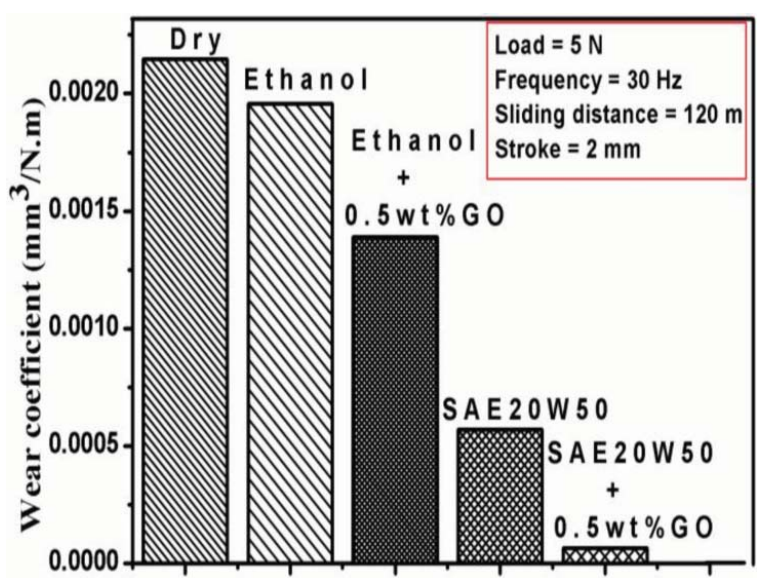

Figure 5. Wear coefficient of the hypereutectic Al-25Si alloy disc.

the weight of disc was measured before and after a sliding time of $16.66 \mathrm{~min}$. The wear volume of disc was calculated from weight loss and density. The wear coefficient was calculated using Eq. [1]. The values of the wear coefficient obtained for hypereutectic $\mathrm{Al}-25 \mathrm{Si}$ alloy disc under dry and lubricated conditions with ethanol, ethanol $+0.5 \mathrm{wt} \%$, SAE20W50, and SAE20W50+ $0.5 \mathrm{wt} \%$ GO under an applied normal load of $5 \mathrm{~N}$ at an oscillating frequency of $30 \mathrm{~Hz}$ are shown in Fig. 5. It can be seen from Fig. 5 that the highest wear coefficient was obtained $\left(2.1 \times 10^{-3} \mathrm{~mm}^{3} / \mathrm{N} . \mathrm{m}\right)$ for Al-25Si alloy under dry sliding conditions. Wear coefficients of $1.9 \times 10^{-3}\left(\mathrm{~mm}^{3} / \mathrm{N} . \mathrm{m}\right)$ and $1.3 \times 10^{-3}\left(\mathrm{~mm}^{3} / \mathrm{N} . \mathrm{m}\right)$ were obtained for Al-25Si alloy when lubricated with ethanol and ethanol $+0.5 \mathrm{wt} \% \mathrm{GO}$, respectively, whereas wear coefficients of $5.6 \times 10^{-4}\left(\mathrm{~mm}^{3} / \mathrm{N}\right.$. $\mathrm{m})$ and $6.3 \times 10^{-5}\left(\mathrm{~mm}^{3} / \mathrm{N} . \mathrm{m}\right)$ were obtained for Al-25Si alloy when lubricated with SAE20W50 and SAE20W50 + $0.5 \mathrm{wt} \%$ $\mathrm{GO}$, respectively. It is clear that the lowest wear coefficient of $6.3 \times 10^{-5}\left(\mathrm{~mm}^{3} / \mathrm{N} . \mathrm{m}\right)$ was obtained for Al-25Si alloy with SAE20W50 + $0.5 \mathrm{wt} \%$ GO compared to dry testing and ethanol, ethanol $+0.5 \mathrm{wt} \% \mathrm{GO}$, and SAE20W50.

\section{Analysis of friction and wear}

\section{Analysis of friction}

Figures 6-10 present SEM micrographs of the rubbing surfaces in dry and lubricated conditions of ethanol and SAE20W50. Figures $6 \mathrm{a}$ and $6 \mathrm{~b}$ show SEM and EDS of wear tracks of Al-25Si under dry sliding conditions. It is evident from the material composition of wear track (Fig. 6b) and material composition of hypereutectic Al-25Si alloy (Table 1) that no significant change in material composition of the alloy has taken place. Therefore, metal-to-metal contact between the Al-25Si alloy disc and steel ball exists, which results in the highest COF. In case of lubrication of the tribopair with ethanol, a higher COF of 0.20 was observed (Fig. 4). This is attributed to evaporation of ethanol with running time, which culminates in direct contact of hypereutectic Al-25Si with steel. The EDS analysis of wear track shown in Figs. $7 \mathrm{~b}-7 \mathrm{c}$ also proves that ethanol is absent at the wear track. However, a reduction in $\mathrm{COF}$ from 0.2 to 0.16 in the case of $\mathrm{Al}-25 \mathrm{Si}$ alloy against steel when 

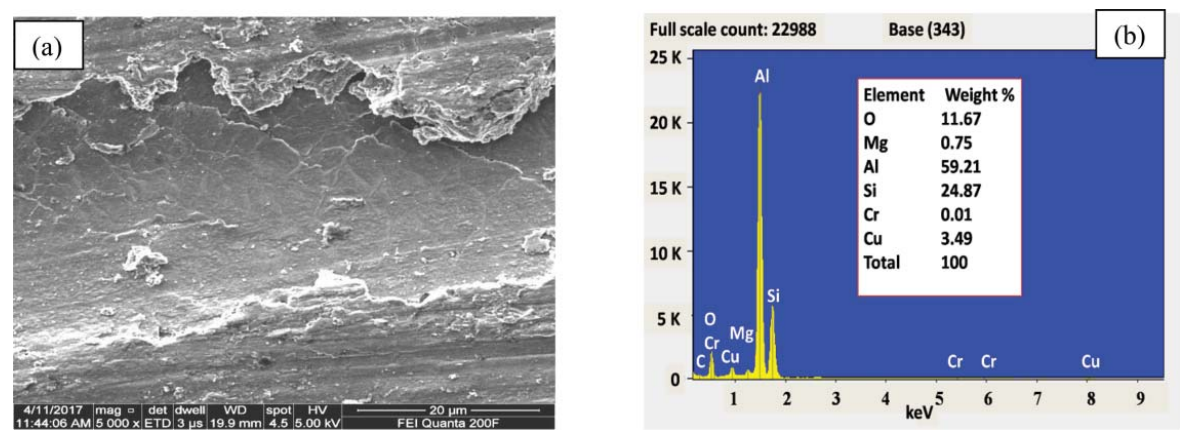

Figure 6. (a) SEM micrograph and (b) EDS spectrum of hypereutectic AI-25Si alloy disc at $5 \mathrm{~N}$ load under dry sliding condition.

lubricated with 0.5 wt $\%$ GO + ethanol was observed due to the antifriction property of GO, which is present on the wear track as shown in EDS (Fig. 8b) and confirmed by Raman spectroscopy (Fig. 11a). A significant decrease in COF was obtained in the case of SAE20W50 with and without GO (Fig. 4). The decrease in COF in the case of SAE20W50 is attributed to the formation of a thin film of lubricant as shown in Figs. 9a and $9 \mathrm{~b}$. The results obtained from this study show a good degree of agreement with the results obtained in earlier research studies (Barnhill, et al. (9); Wan, et al. (10); Charoo and Wani (11), (12)). However, the lowest COF (0.05) was observed in the case of SAE20W50 $+0.5 \mathrm{wt} \% \mathrm{GO}$. The reduction in COF is due to the presence of GO in SAE20W50. The presence of GO particles on the wear track is clearly visible in SEM images (Fig. 10a) and is also confirmed by EDS and Raman spectroscopy, shown in Figs. $10 \mathrm{~b}$ and $11 \mathrm{~b}$, respectively. It was found that at the interface, a surface-protective layer of GO is formed due to adsorption on the wear track. The two-dimensional sheet shape of GO provides very easy shear due to weak Van der Waals forces and more easily acts as a slider between the two mating surfaces, which results in a reduction of COF. The reduction of $\mathrm{COF}$ due to adsorption of $\mathrm{GO}$ at the interface surface is also confirmed in studies by Berman, et al. (27), (28), Fan and Wang (29); Senatore, et al. (32), Sarno, et al. (33), Fan, et al. (34), Zhe, et al. (35), and Chu, et al. (39).

\section{Analysis of wear}

Figures 12a-12j show optical micrographs of the wear tracks of the hypereutectic Al-25Si alloy disc and steel ball. In the case of dry and ethanol-lubricated sliding conditions, the highest wear was observed due to direct contact at the asperity level between aluminum and steel, which increases wear because aluminum is prone to adhere to steel surfaces. This is attributed to the
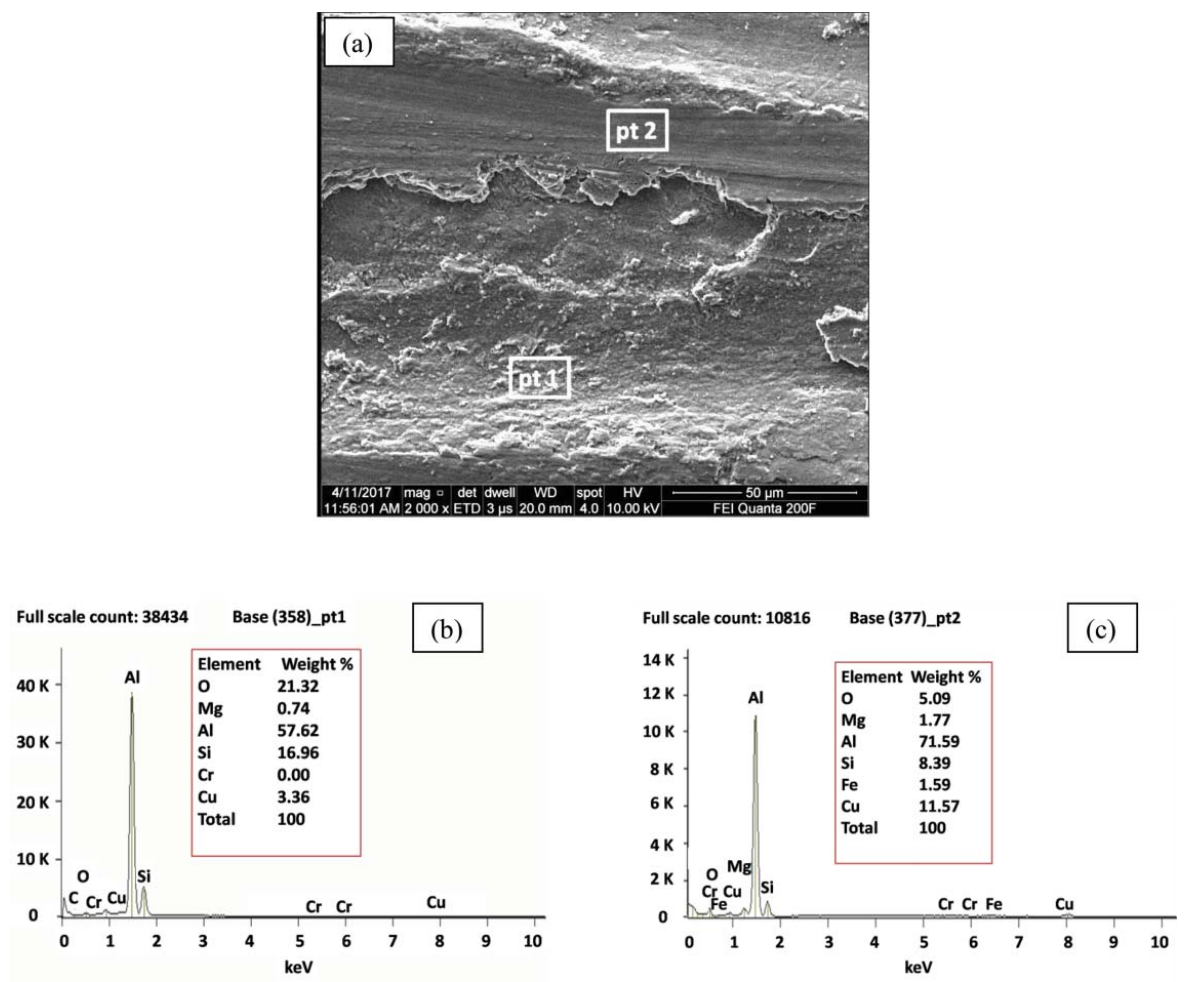

Figure 7. (a) SEM micrograph and (b)-(c) EDS spectrum at two different points for the hypereutectic Al-25Si alloy disc at $5 \mathrm{~N}$ load under ethanol-lubricated sliding condition. 

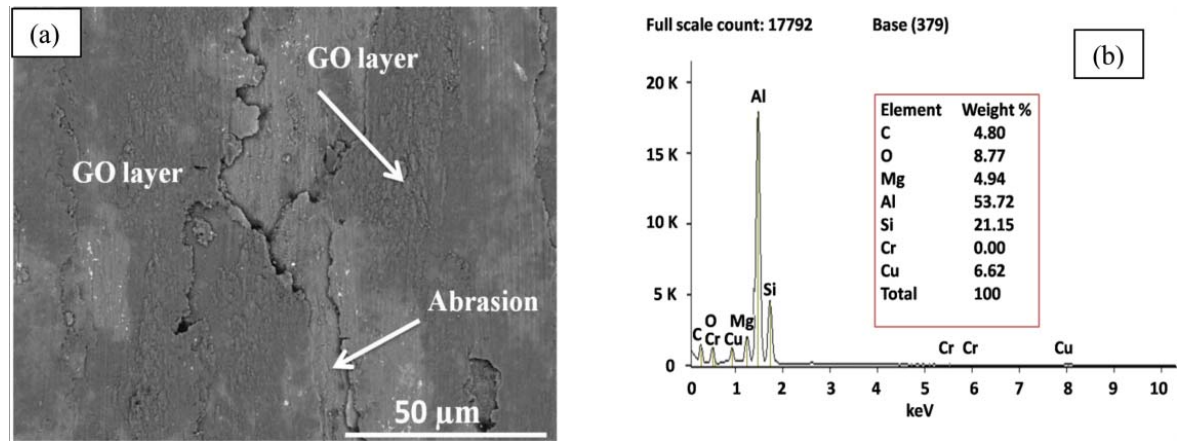

Figure 8. (a) SEM micrograph and (b) EDS spectrum of the hypereutectic Al-25Si alloy disc at $5 \mathrm{~N}$ load under ethanol +0.5 wt $\%$ GO-lubricated sliding condition.
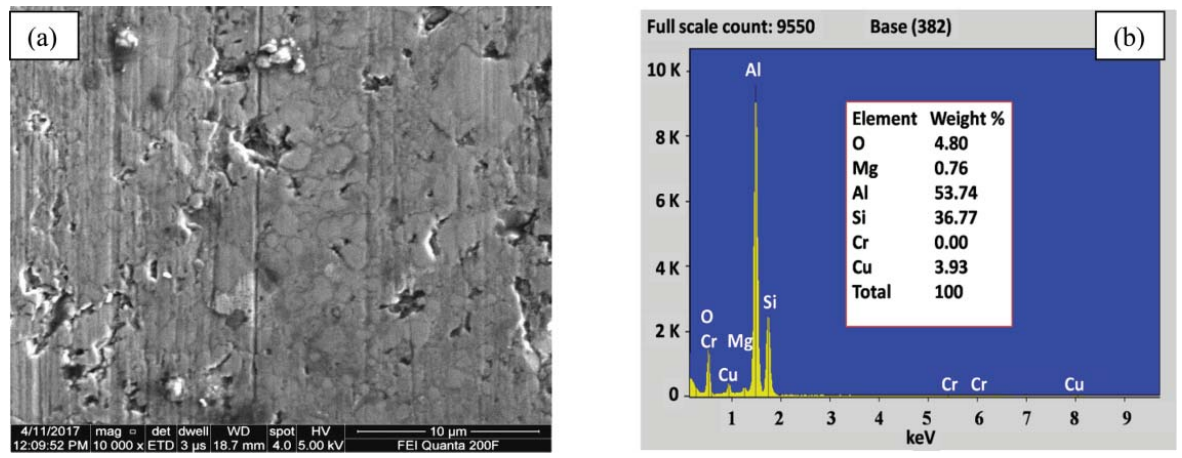

Figure 9. (a) SEM micrograph and (b) EDS spectrum of the hypereutectic Al-25Si alloy disc at $5 \mathrm{~N}$ load under SAE20W50 engine oil-lubricated sliding condition.

mutual high solid solubility of aluminum and steel. It is well known that the higher the solubility, the higher the adhesion between two metallic surfaces, which results in higher wear (Shabel et al. (40); Robinowicz (41)). This indicates the mutual transfer of material between mating surface as shown in optical micrographs (Figs. 12a-12d). SEM images (Figs. 6a and 7a) and optical micrographs (Figs. 12a-12d) of the wear tracks of dry and ethanol-lubricated surfaces indicate severe abrasion, severe plastic deformation of the surface, deep scuffing, and cracking, indicating the occurrence of metallic wear and severely deep scratches due to the direct contact of the alloy disc and the steel ball. Severe wear damage can be observed on the hypereutectic Al-25Si alloy disc in dry and ethanol-lubricated conditions without GO particles and the wear damage became insignificant. The EDS analysis of dry conditions and ethanol and SAE20W50 oil showed that no C element content was present on the wear tracks, as shown in Figs. 6b, 7b-7c, and $9 \mathrm{~b}$, which reveal that no protective layer was formed, thus leading to a high wear coefficient. In the case of ethanol + $0.5 \mathrm{wt} \% \mathrm{GO}$, the rubbing surface (shown in Fig. 8a and Figs. 12e and 12f) was smoother than that as shown in Fig. $7 \mathrm{a}$ and Figs. $12 \mathrm{c}$ and $12 \mathrm{~d}$, but it still showed obvious scratches and extensive furrows, which lead to high wear. A very thin layer of GO was formed as shown in Fig. 8a (green ring), confirmed by the EDS analysis in Fig. $8 \mathrm{~b}$ depicting $4.80 \mathrm{wt} \%$ of $\mathrm{C}$ element on the hypereutectic Al-25Si alloy surface.

It can be observed from SEM images (Fig. 9a) and optical micrographs (Figs. $12 \mathrm{~g}$ and $12 \mathrm{~h}$ ) that the worn surfaces lubricated with the SAE20W50 oil acquired more dense wear scars and grooves, which were dominated to abrasive wear. As shown in Fig. 10a and Figs. 12i and 12j, the worn surface lubricated with SAE20W50 + $0.5 \mathrm{wt} \%$ GO shows a
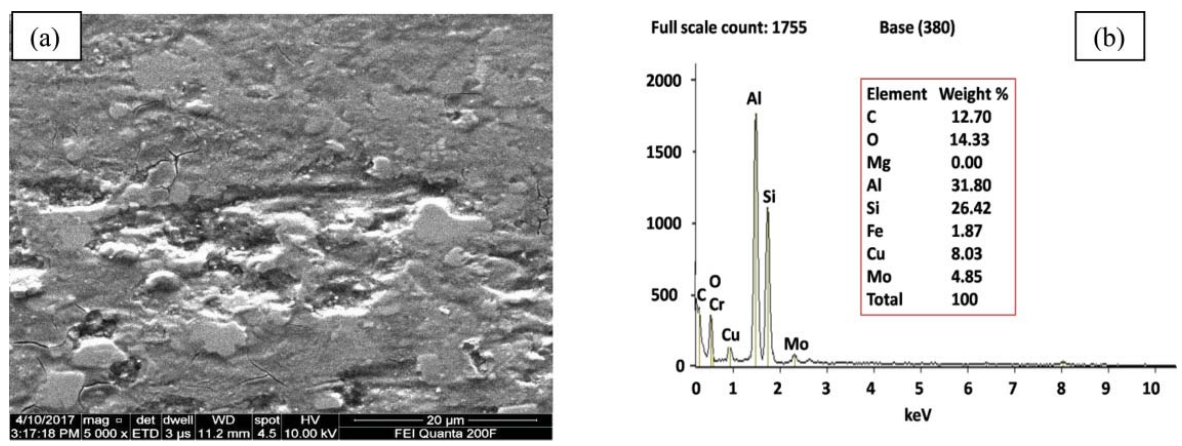

Figure 10. (a) SEM micrograph and (b) EDS spectrum of the hypereutectic Al-25Si alloy disc at $5 \mathrm{~N}$ load under SAE20W50 + 0.5 wt $\%$ GO-lubricated sliding condition. 

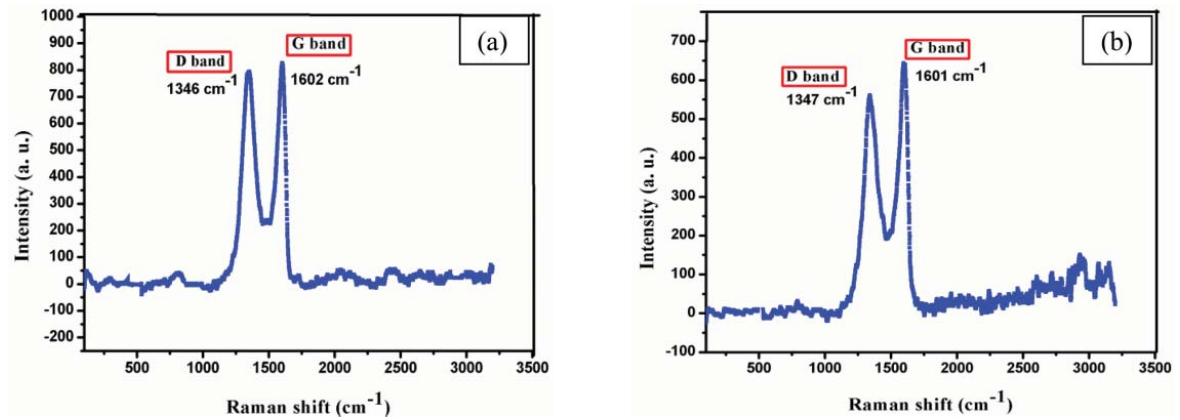

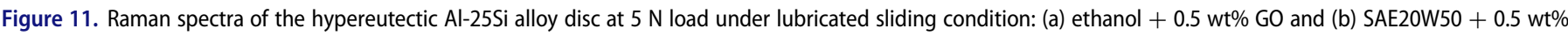
GO.

smaller and smoother wear track. This leads to the formation of a protective film that prevents the rubbing surfaces from coming into direct contact and significantly enhances the tribological behavior of the SAE20W50 oil. The EDS analysis of GO with SAE20W50 oil as shown in Fig. 10b displayed a $\mathrm{C}$ element content of $12.70 \%$, higher than that found in ethanol $+0.5 \mathrm{wt} \% \mathrm{GO}$, which confirmed the formation of a protective layer due to the presence of GO particles on the wear track. The wear track width in the case of SAE20W50 + $0.5 \mathrm{wt} \%$ Go (Fig. 12i) is five times smaller than that of the wear track obtained in dry sliding condition (Fig. 12a). However, a negligible wear scar was observed on the steel ball in the case of GO as additive in SAE20W50 oil (Fig. 12j), which is attributed to the higher wear resistance of the ball material due to its higher hardness (HRC 59-63 = 670-770 HV) value in comparison to the hypereutectic Al-25Si alloy disc $(210 \mathrm{HV})$. As shown in Figs. $12 \mathrm{~g}$ and $12 \mathrm{i}$, a lower wear track width of $184.770 \mu \mathrm{m}$ was observed in the case of SAE20W50 + GO compared to the wear track width of $252.969 \mu \mathrm{m}$ observed in the case of ethanol + GO. The reduction in wear due to the presence of GO at the interface surface is also confirmed in research by Berman, et al. (27), (28), Fan and Wang (29); Senatore, et al. (32), Sarno, et al. (33), Fan, et al. (34), Zhe, et al. (35), and $\mathrm{Chu}$, et al. (39).

Figures $13 \mathrm{a}-13 \mathrm{e}$ present $3 \mathrm{D}$ profilometer images and the surface texture of the wear tracks of hypereutectic Al-25Si alloy disc. In dry sliding condition, high values of $R_{a}(14.5 \mu \mathrm{m})$ and $W_{a}(32.5 \mu \mathrm{m})$ were obtained as shown in Fig. 13a. Figures $13 \mathrm{~b}$ and $13 \mathrm{c}$ show $R_{a}$ values of 13.3 and $10.9 \mu \mathrm{m}$ and $W_{a}$ values of 26.6 and $20.4 \mu \mathrm{m}$ in the case of ethanol and ethanol $+0.5 \mathrm{wt} \% \mathrm{GO}$, respectively, whereas lower $R_{a}$ values of 0.104 and $0.092 \mu \mathrm{m}$ and lower $W_{a}$ values of 0.143 and 0.113 were attained in the case of SAE20W50 and SAE20W50 + $0.5 \mathrm{wt} \%$ GO, respectively (shown in Figs. 13d and 13e). The surface roughness value decreased from $14.5 \mu \mathrm{m}$ (dry condition as shown in Fig. 13a) to 0.092 (SAE20W50 + $0.5 \mathrm{wt} \%$ $\mathrm{GO}$ as shown in Fig. 13e). In addition, the surface waviness $\left(W_{a}\right)$ value decreased from $32.5 \mu \mathrm{m}$ (dry condition) to $0.113 \mu \mathrm{m}$ (SAE20W50 + $0.5 \mathrm{wt} \% \mathrm{GO})$. The results indicated that the surface roughness, texture, and waviness of the wear tracks notably decrease with ethanol and SAE20W50, whereas smoother surfaces and minimum wear scar depths were obtained with GO particles. High wear occurs mostly at the interfaces in dry and ethanol-lubricated conditions when no protective layer exists (the width of the scar is $790 \mu \mathrm{m})$.
Further, Raman spectroscopy was carried out to confirm this excellent tribological behavior and the presence of GO particles on the rubbing surface. Raman spectra of the wear tracks after the tribotests with GO in ethanol and SAE20W50 oil are presented in Fig. 11. Raman mapping of these wear tracks shows the concentration and intensity of the D and G peaks of GO after the test. After the tests in ethanol and SAE20W50 oil, the $\mathrm{D}$ band and $\mathrm{G}$ band peaks of $\mathrm{GO}$ were detected everywhere on the wear track. The Raman spectrum of the wear tracks shows the presence of GO, as evidenced from the D band peak intensity in ethanol and SAE20W50 oil (at 1346 and $1347 \mathrm{~cm}^{-1}$, respectively; Figs. 11a and 11b) and the G band peak intensities in ethanol and SAE20W50 oil are obtained at 1602 and $1601 \mathrm{~cm}^{-1}$, respectively.

Previous studies (Kandanur, et al. (22); Liao, et al. (23); in, et al. (24); Prasai, et al. (25); Chen, et al. (26); Berman, et al. (27), (28); Fan and Wang (29); Kinoshita, et al. (30); Zheng, et al. (31); Senatore, et al. (32); Sarno, et al. (33); Fan, et al. (34); Zhe, et al. (35)) of Raman spectrum analysis for friction and wear investigation showed that the characteristic D band peak and G band peak were obtained at 1345 and $1598 \mathrm{~cm}^{-1}$. The Raman spectra of the wear tracks with GO particles (Fig. 11) present very similar peaks in contrast to the steel ball, which confirms the presence of GO particles and reduces friction and wear of the hypereutectic Al-25Si alloy disc. These results indicate that GO particles were barely deposited on the mating surface, which confirms the presence of $\mathrm{GO}$ on the hypereutectic $\mathrm{Al}-25 \mathrm{Si}$ alloy disc and the formation of a continuous protective film as shown in Figs. $8 \mathrm{~b}$ and $10 \mathrm{~b}$ as well as Fig. 11. This proves that a GO layer was stacked on the wear track during reciprocating sliding. The surface morphologies indicate that the addition of GO leads to a smoother surface by reducing the surface roughness. In addition, the two-dimensional sheet shape of GO provides very easy shear due to weak Van der Waal forces and more easily acts as a slider between the two mating surfaces. Therefore, the COF and wear rate of hypereutectic Al-25Si alloy is decreased significantly. Moreover, GO fills the deeper scratches of the alloy and produces a thinner tribofilm. The tribofilm not only withstands the applied normal load but prevents direct contact of the two mating surfaces. This enhances the antifriction and antiwear properties of ethanol/SAE20W50. The reduction in COF and wear due to adsorption of GO at the interface surface is also confirmed in studies by Berman, et al. (27), (28), Fan 

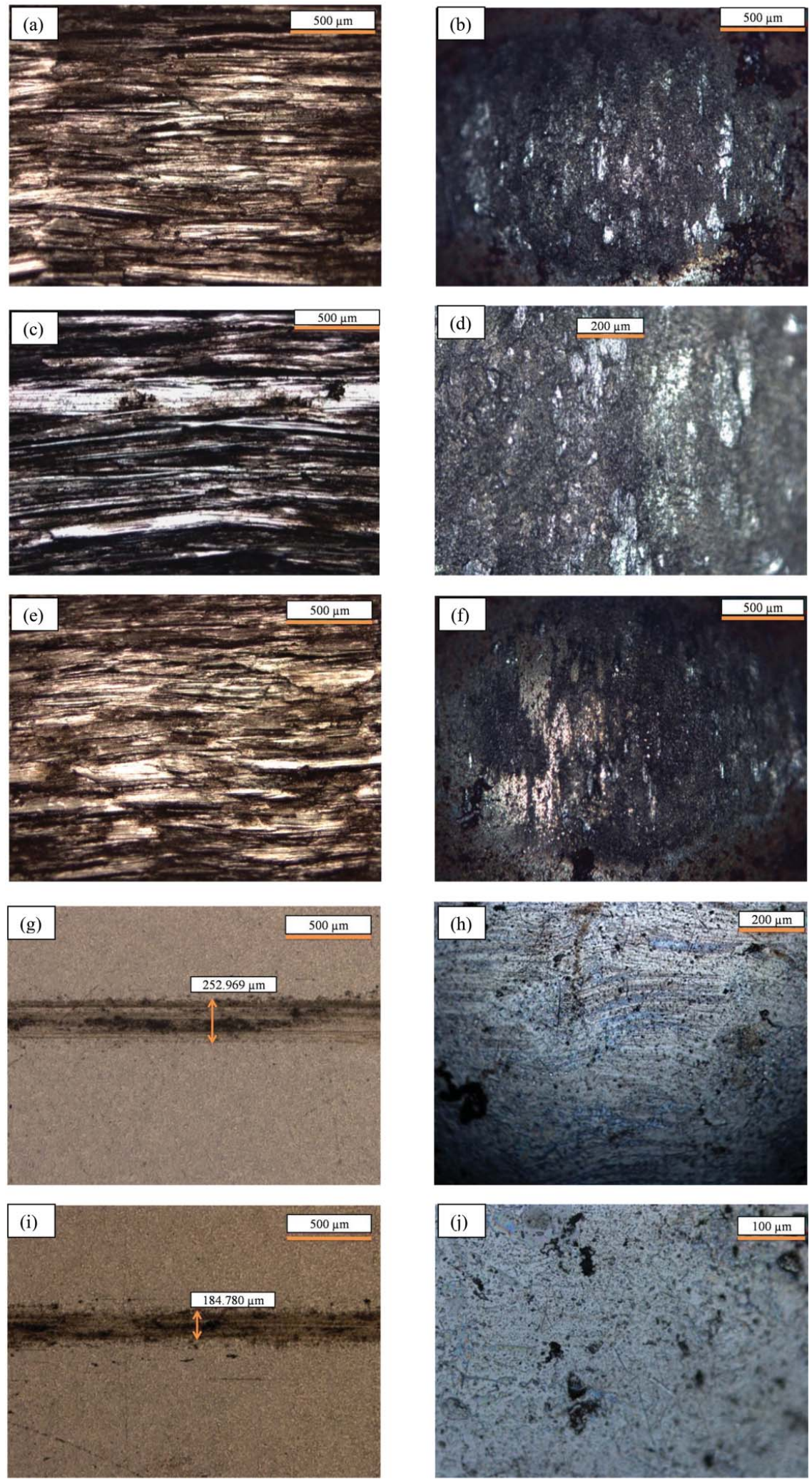

Figure 12. Optical micrographs of the Al-25Si alloy disc and counterbody AISI steel ball at $5 \mathrm{~N}$ load, respectively: (a), (b) disc and ball under dry condition; (c), (d) disc and ball under ethanol-lubricated condition; (e), (f) disc and ball under ethanol + $0.5 \mathrm{wt} \%$ GO-lubricated condition; (g), (h) disc and ball under $20 \mathrm{~W} 50$ engine oil-lubricated condition; (i), (j) disc and ball under $20 \mathrm{~W} 50+0.5 \mathrm{wt} \%$ GO-lubricated condition.

and Wang (29); Senatore, et al. (32), Sarno, et al. (33), Fan, et al. (34), Zhe, et al. (35), and Chu, et al. (39).

It is inferred from these results that GO particles as an additive reduced the wear loss by about $60-80 \%$ compared to that under dry condition. The coefficient of friction for SAE20W50 + $0.5 \mathrm{wt} \%$ GO is the lowest (0.057) throughout the testing process compared to dry and ethanol-lubricated conditions. The antiwear property of GO as an additive in 

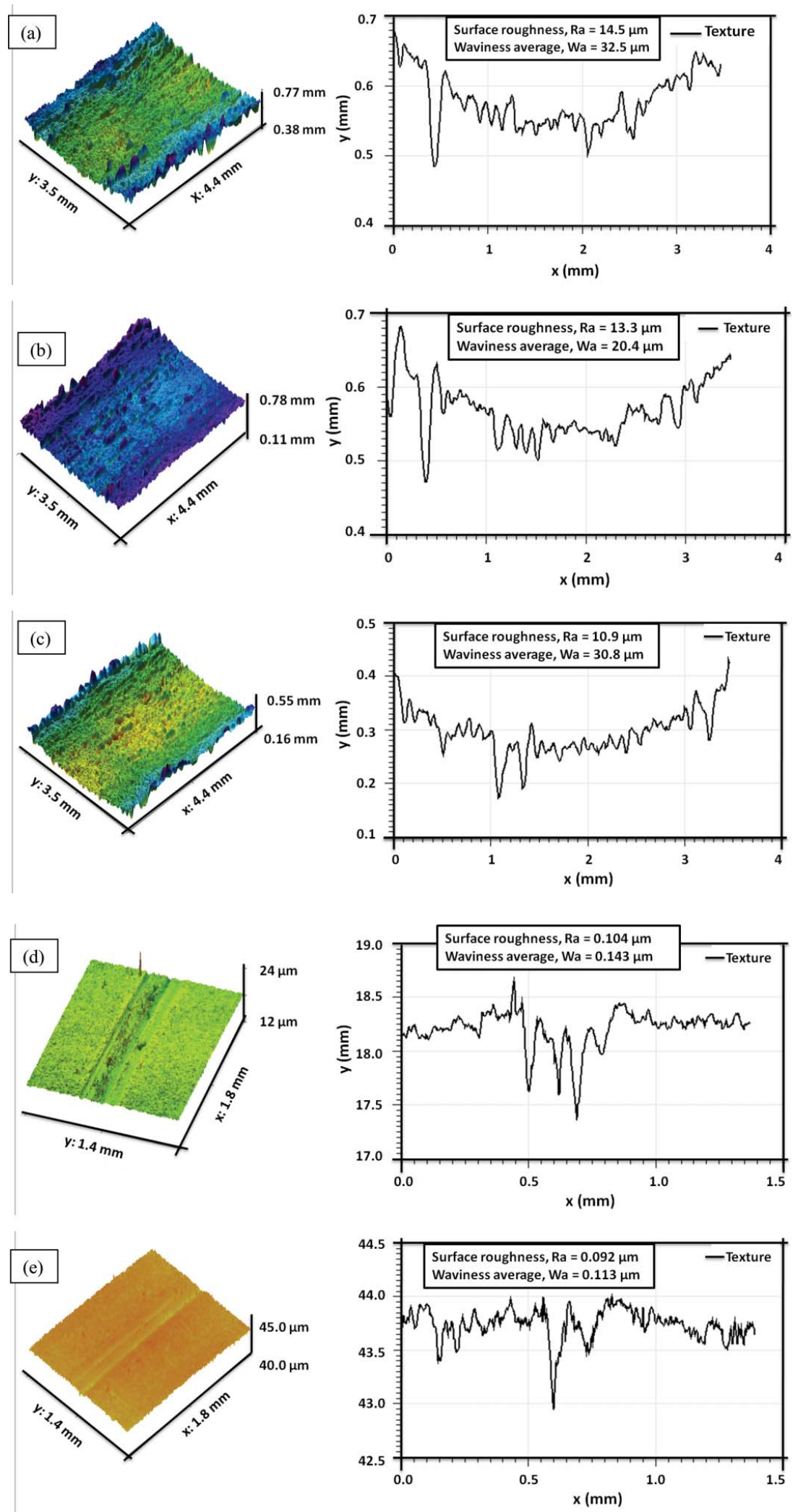

Figure 13. 3D profilometer image and surface texture of the hypereutectic Al-25Si alloy disc at $5 \mathrm{~N}$ load at $5 \mathrm{~N}$ load: (a) under dry condition, (b) under ethanol lubricated condition, (c) under ethanol + 0.5 wt\% GO-lubricated condition, (d) under 20 W50 engine oil-lubricated condition, and (e) under 20W50 + 0.5 wt\% GO-lubricated condition.

ethanol and SAE20W50 oil lubricants has been clearly exhibited in the boundary lubrication regimes. These results show that GO possesses excellent friction-reducing and antiwear properties.
From the above discussion it is evident that GO provides a new pathway for improvement in the wear and friction properties that could be further implemented for many industrial applications involving rotational and reciprocating sliding contacts. 


\section{Conclusions}

Friction and wear studies were conducted to understand the lubrication effect and mechanism of GO in the case of a hypereutectic Al-25Si alloy disc-steel ball tribopair. The improved Tour method was used for synthesis of GO. A substantial reduction in $\mathrm{COF}$ was observed in the case of the tribopair lubricated with GO. Wear of the rubbing surfaces was substantially reduced $(60-80 \%)$ and the COF decreased from 0.22 to 0.057 due to the presence of GO at the tribological interface. 3D surface profilometry, SEM, EDS, and Raman spectroscopy revealed the presence of GO. These results indicate a passivation effect due to the GO layers, which not only helped to reduce the $\mathrm{COF}$ of the tribopair but provided easy shearing and thus resulted in improved friction. GO constitutes a new class of lubricant that is less harmful, corrosion resistant, and easy to use for Al-Si alloys. The beneficial effect of GO to drastically reduce the friction and wear can be potentially applied in engine components. This opens up new opportunities for GO as a self-lubricant in automobile applications and other mechanical assemblies.

\section{References}

(1) Yoshizawa, H., Chen, Y. L., and Israelachvili, J. (1993), "Fundamental Mechanisms of Interfacial Friction: Relation between Adhesion and Friction," The Journal of Physical Chemistry, 97(16), pp 4128-4140.

(2) Willing, A. (2001), "Lubricants Based on Renewable Resources-An Environmentally Compatible Alternative to Mineral Oil Products," Chemosphere, 43(1), pp 89-98.

(3) Mercurio, P., Burns, K. A., and Negri, A. (2004), "Testing the Ecotoxicology of Vegetable versus Mineral Based Lubricating Oils: Degradation Rates Using Tropical Marine Microbes," Environmental Pollution, 129(2), pp 165-173.

(4) Bartz, W. J. (1998), "Lubricants and the Environment," Tribology International, 31(1), pp 35-47.

(5) Greenberg, R., Halperin, G., Etsion, I., and Tenne, R. (2004), "The Effect of $\mathrm{WS}_{2}$ Nanoparticles on Friction Reduction in Various Lubrication Regimes," Tribology Letters, 17(2), pp 179-186.

(6) Joly-Pottuz, L., Dassenoy, F., Belin, M., Vacher, B., Martin, J. M., and Fleischer, N. (2005), "Ultralow-Friction and Wear Properties of IF$\mathrm{WS}_{2}$ under Boundary Lubrication," Tribology Letters, 18(4), pp 477485.

(7) Yadgarov, L., Petrone, V., Rosentsveig, R., Feldman, Y., Tenne, R., and Senatore, A. (2013), "Tribological Studies of Rhenium Doped Fullerene-Like $\mathrm{MoS}_{2}$ Nanoparticles in Boundary, Mixed and ElastoHydrodynamic Lubrication Conditions," Wear, 297(1), pp 11031110.

(8) Rosentsveig, R., Gorodnev, A., Feuerstein, N., Friedman, H., Zak, A., Fleischer, N., Tannous, J., Dassenoy, F., and Tenne, R. (2009), "Fullerene-Like $\mathrm{MoS}_{2}$ Nanoparticles and Their Tribological Behavior," Tribology Letters, 36(2), pp 175-182.

(9) Barnhill, W. C., Gao, H., Kheireddin, B., Papke, B. L., Luo, H., West, B. H., \& Qu, J. (2015), "Tribological Bench and Engine Dynamometer Tests of a Low Viscosity SAE0W-16 Engine Oil Using a Combination of Ionic Liquid and ZDDP as Anti-Wear Additive," Frontiers in Mechanical Engineering, 1(12), pp 1-8

(10) Wan, Q., Jin, Y., Sun, P., and Ding, Y. (2015), "Tribological Behaviour of a Lubricant Oil Containing Boron Nitride Nanoparticles," Journal of Procedia Engineering, 102, pp 1038-1045.

(11) Charoo, M. S. and Wani, M. F. (2016), "Tribological Properties of IF$\mathrm{MoS}_{2}$ Nanoparticles as Lubricant Additive on Cylinder Liner and Piston Ring Tribo-Pair," Tribology in Industry, 38(2), pp 156-162.

(12) Charoo, M. S. and Wani, M. F. (2016), "Tribological Properties of hBN Nanoparticles as Lubricant Additive on Cylinder Liner and Piston Ring," Lubrication Science, 29(4), pp 241-254.
(13) Khorramian, B. A., Iyer, G. R., Kodali, S., Natarajan, P., and Tupil, R. (1993), "Review of Antiwear Additives for Crankcase Oils," Wear, 169(1), pp 87-95.

(14) Peng, B., Locascio, M., Zapol, P., Li, S., Mielke, S. L., Schatz, G. C., and Espinosa, H. D. (2008), "Measurements of Near-Ultimate Strength for Multiwalled Carbon Nanotubes and Irradiation-Induced Crosslinking Improvements," Nature Nanotechnology, 3(10), pp 626-631.

(15) Schwarz, U. D., Zwörner, O., Köster, P., and Wiesendanger, R. (1997), "Quantitative Analysis of the Frictional Properties of Solid Materials at Low Loads," Physical Review B, 56(11), pp 6987-6992.

(16) Yu, M. F., Lourie, O., Dyer, M. J., Moloni, K., Kelly, T. F., and Ruoff, R. S. (2000), "Strength and Breaking Mechanism of Multiwalled Carbon Nanotubes under Tensile Load," Science, 287 (5453), pp 637-640.

(17) Lee, C., Wei, X., Kysar, J. W., and Hone, J. (2008), "Measurement of the Elastic Properties and Intrinsic Strength of Monolayer Graphene," Science, 321(5887), pp 385-388.

(18) Gómez-Navarro, C., Burghard, M., and Kern, K. (2008), "Elastic Properties of Chemically Derived Single Graphene Sheets," Nano Letters, 8(7), pp 2045-2049.

(19) Gao, Y. and Hao, P. (2009), "Mechanical Properties of Monolayer Graphene under Tensile and Compressive Loading," Physica E: LowDimensional Systems and Nanostructures, 41(8), pp 1561-1566.

(20) Lee, C., Wei, X., Li, Q., Carpick, R., Kysar, J. W., and Hone, J. (2009), "Elastic and Frictional Properties of Graphene," Physica Status Solidi $B$, 246(11-12), pp 2562-2567.

(21) Deng, Z., Smolyanitsky, A., Li, Q., Feng, X. Q., and Cannara, R. J. (2012), "Adhesion-Dependent Negative Friction Coefficient on Chemically Modified Graphite at the Nanoscale," Nature Materials, 11(12), pp 1032-1037.

(22) Kandanur, S. S., Rafiee, M. A., Yavari, F., Schrameyer, M., Yu, Z. Z., Blanchet, T. A., and Koratkar, N. (2012), "Suppression of Wear in Graphene Polymer Composites," Carbon, 50(9), pp 3178-3183.

(23) Liao, Y., Pourzal, R., Wimmer, M. A., Jacobs, J. J., Fischer, A., and Marks, L. D. (2011), "Graphitic Tribological Layers in Metal-on-Metal Hip Replacements," Science, 334(6063), pp 1687-1690.

(24) Lin, J., Wang, L., and Chen, G. (2011), "Modification of Graphene Platelets and Their Tribological Properties as a Lubricant Additive," Tribology Letters, 41(1), pp 209-215.

(25) Prasai, D., Tuberquia, J. C., Harl, R. R., Jennings, G. K., and Bolotin, K. I. (2012), "Graphene: Corrosion-Inhibiting Coating," ACS Nano, 6(2), pp 1102-1108.

(26) Chen, S., Brown, L., Levendorf, M., Cai, W., Ju, S. Y., Edgeworth, J., Li, X., Magnuson, C. W., Velamakanni, A., Piner, R. D., and Kang, J. (2011), "Oxidation Resistance of Graphene Coated $\mathrm{Cu}$ and $\mathrm{Cu} / \mathrm{Ni}$ Alloy," ACS Nano, 5(2), pp 1321-1327.

(27) Berman, D., Erdemir, A., and Sumant, A. V. (2013), "Few Layer Graphene to Reduce Wear and Friction on Sliding Steel Surfaces," Carbon, 54, pp 454-459.

(28) Berman, D., Erdemir, A., and Sumant, A. V. (2013), "Reduced Wear and Friction Enabled by Graphene Layers on Sliding Steel Surfaces in Dry Nitrogen," Carbon, 59, pp 167-175.

(29) Fan, X. and Wang, L. (2015), "High-Performance Lubricant Additives Based on Modified Graphene Oxide by Ionic Liquids," Journal of Colloid and Interface Science, 452, pp 98-108.

(30) Kinoshita, H., Nishina, Y., Alias, A. A., and Fujii, M. (2014), "Tribological Properties of Monolayer Graphene Oxide Sheets as WaterBased Lubricant Additives," Carbon, 66, pp 720-723.

(31) Zheng, D., Cai, Z. B., Shen, M. X., Li, Z. Y., and Zhu, M. H. (2016) "Investigation of the Tribology Behaviour of the Graphene Nanosheets as Oil Additives on Textured Alloy Cast Iron Surface," Applied Surface Science, 387, pp 66-75.

(32) Senatore, A., D'Agostino, V., Petrone, V., Ciambelli, P., and Sarno, M. (2013), "Graphene Oxide Nanosheets as Effective Friction Modifier for Oil Lubricant: Materials, Methods, and Tribological Results," ISRN Tribology, 2013, pp 1-9. 
(33) Sarno, M., Senatore, A., Cirillo, C., Petrone, V., and Ciambelli, P. (2014), "Oil Lubricant Tribological Behaviour Improvement through Dispersion of Few Layer Graphene Oxide," Journal of Nanoscience and Nanotechnology, 14(7), pp 4960-4968.

(34) Fan, X., Xia, Y., Wang, L., and Li, W. (2014), "Multilayer Graphene as a Lubricating Additive in Bentone Grease," Tribology Letters, 55(3), pp 455-464.

(35) Zhe, C., Yuhong, L., and Jianbin, L. (2015), “Tribological Properties of Few-Layer Graphene Oxide Sheets as Oil-Based Lubricant Additives," Chinese Journal of Mechanical Engineering, 1028, pp 129-135.

(36) Chandra, V. and Kim, K. S. (2011), "Highly Selective Adsorption of Hg 2+ by a Polypyrrole-Reduced Graphene Oxide Composite," Chemical Communications, 47(13), pp 3942-3944.
(37) Paulchamy, B., Arthi, G., and Lignesh, B. D. (2015), "A Simple Approach to Stepwise Synthesis of Graphene Oxide Nanomaterial," Journal of Nanomedicine \& Nanotechnology, 6(1), pp 1-4.

(38) Marcano, D. C., Kosynkin, D. V., Berlin, J. M., Sinitskii, A., Sun, Z., Slesarev, A., Alemany, L. B., Lu, W., and Tour, J. M. (2010), "Improved Synthesis of Graphene Oxide," ACS Nano, 4(8), pp 4806-4814.

(39) Chu, S., Jin, Z., and Xue, Q. (1997), "Study of the Interaction between Natural Flake Graphite and Oil Soluble Additives," Tribology Beijing, 17, pp 340-347.

(40) Shabel, B. S., Granger, D. A., and Truckner, W. G. (1992), "Friction, Lubrication, and Wear Technology," In Henry, S.D. (Ed.), ASM Handbook, pp 785, ASM International Handbook Committee. Vol. 18, pp 785-795.

(41) Robinowicz, E. (1971), "Determination of Compatibility of Metals through Static Friction Tests," ASLE Transactions, 14, pp 198-205. 